Cadernos de Clio, Curitiba, v. 9, nº 1, 2018

\title{
IVAN TURGUENIEV E O PENSAMENTO RUSSO DO SÉCULO XIX, UMA ANÁLISE A PARTIR DO ROMANCE PAIS E FILHOS
}

\section{IVAN TURGUENIEV AND 19 ${ }^{\text {TH }}$ CENTURY RUSSIAN THOUGHT, AN ANALYSIS OF THE NOVEL FATHERS AND SONS}

Letícia Schevisbisky de Souza ${ }^{1}$

Resumo: Esse artigo é resultado de um trabalho escrito conjuntamente para as disciplinas de Teoria da História III e História Contemporânea I na Universidade Federal do Paraná (UFPR). Para a realização desse trabalho, cada aluno deveria ler um romance do século XIX e perceber os elementos da narrativa que demonstrassem aspectos que constituíram as sociedades do período. Ivan Turgueniev escrevia seus romances sobre o presente e foi um escritor atuante nos círculos intelectuais russos e europeus no século XIX. A partir dessa constatação, esse artigo busca identificar os elementos do romance Pais e Filhos que se relacionam com as questões intelectuais russas relevantes no período. Em seguida, o artigo busca defender a relevância da análise historiográfica dos romances dessa mesma periodização.

Palavras-chave: Romance; Pensadores russos; Pais e Filhos.

Abstract: This article is the result of a paper made for both disciplines Historical Theory III and Contemporary History I in the Federal University of Paraná. In order to make this paper, every student would read a $19^{\text {th }}$ century novel and notice some elements of the narrative that displaced constituent aspects of the societies in those times. Ivan Turgueniev wrote his romances about the present and he was an active member of Russian and European intellectual circles in the $19^{\text {th }}$ century. Thus, this article seeks to identify the elements in the novel Fathers and Sons that relate to the

\footnotetext{
${ }^{1}$ Graduanda em História - Licenciatura e Bacharelado pela Universidade Federal do Paraná.
} 
relevant intellectual issues in the period. Furthermore, this article seeks to defend the relevance of historical analysis of novels from this time period. Keywords: Novel; Russian scholars, Fathers and Sons.

\section{Introdução}

Ivan Turgueniev nasceu em 1818 em Oryol, no Império Russo. Filho de uma família nobre, estudou nas universidades de Moscou e de São Petersburgo entre 1834 e 1837. Suas áreas de enfoque eram estudos clássicos, literatura russa e filologia. Posteriormente (entre 1838 e 1841), estudou filosofia hegeliana e história na Universidade de Berlim. O romance Pais e Filhos foi publicado em 1862, após acontecimentos importantes na Europa como a Primavera dos Povos, a publicação do Manifesto Comunista, Guerras Napoleônicas e a batalha da Crimeia, entre outros. Segundo o historiador Isaiah Berlin (1988), apesar de Turgueniev ter estudado Hegel, entrado em contato com o positivismo e convivido nos mesmos círculos de intelectuais como Bakunin e Dostoiévski, voltou-se para o realismo e procurou explorar as controvérsias morais e políticas das pessoas de seu tempo nos seus escritos. Para esse autor, Turgueniev possuía alto grau de Einfühlen (empatia, segundo o conceito de Herder) que permitia que compreendesse crenças avessas às dele próprio (BERLIN, 1988). Seu primeiro romance dentro dessa linha que garantiu muito sucesso foi Cenas de um Desportista em 1852; Pais e Filhos, entretanto, é considerado sua obra-prima.

A história do livro se passa em 1859 e acompanha dois protagonistas, o niilista Eugênio Bazárov e seu discípulo Arcádio Nicoláievitch, em três visitas. A primeira é prestada a Nicolau e Páviel 
Cadernos de Clio, Curitiba, v. 9, nº. 1, 2018

Petróvitch (pai e tio de Arcádio, respectivamente). A segunda é à residência da dama aristocrata Ana Odintsova, sua irmã caçula Cátia e sua tia Princesa K. A terceira é aos pais de Bazárov, Vassíli Ivánovitch e Arina Vassílievna.

\section{$O$ autor, as personagens e o contexto}

Ivan Turgueniev foi um autor Realista que escrevia sobre seu próprio tempo. Pais e Filhos é um livro de 1862 que se passa em 1859 e lida com as contradições entre duas gerações de pensadores: os dos anos 1840 e os dos anos 1860. Essa oposição entre velho e novo é vivida pelo próprio Turgueniev, que, como Realista, busca retratá-la com todas as suas contradições internas - apontando continuidades e rupturas. Para melhor compreender as mudanças que ocorreram no pensamento intelectual russo, é necessário voltar ao final do século XVIII com as políticas de Pedro, o Grande. Segundo o historiador Michael Confino (1972), essas políticas buscavam estabelecer uma diferença entre a "velha" e a "nova" Rússia, além de tirar o monopólio das produções intelectuais da Igreja. Isso seria realizado pelo incentivo à ida de intelectuais para países do oeste europeu para que fossem educados sob os padrões lá vigentes. O objetivo do monarca era que, com esse incentivo, fosse formada uma nova tradição e por isso incentivava todas as manifestações contra as bases do regime anterior, havendo uma grande e bem recebida entrada de ideias do oeste europeu para dentro da Rússia (CONFINO, 1972).

Além da morte de Pedro em 1775, o final do século também trouxe algumas mudanças nessa tradição intelectual russa: o aumento do número de intelectuais nobres; o maior desenvolvimento da historiografia russa 
(principalmente por parte de historiadores que haviam estudado em países germânicos); maior número de cientistas; e, principalmente, um medo das ideias ocidentais manifestado pelas autoridades. Esse último aspecto levou à maior restrição do conhecimento, reforçada por um sistema de polícia secreta. Em dezembro de 1825, após Alexandre I ter se tornado czar, levantou-se contra ele a Revolta Dezembrista, encabeçada por oficiais do exército a favor de uma constituição. Apesar de ter sido facilmente reprimido, esse evento - em adição às outras revoltas e revoluções que aconteceram na Europa nos próximos anos - levou o czar a conceber as ideias do ocidente como ameaças à integridade de seu governo, intensificando a censura sobre elas.

Devido a essas mudanças, os intelectuais passam de uma atitude disruptiva para uma que se mantinha mais fiel ao governo. Dado o aumento da censura, os pensadores sociais e políticos se transformaram em poetas e romancistas; e a literatura, de acordo com Berlin (1988), se tornou o campo de discussão das questões sociais e políticas, apesar de não abertamente ir contra o governo. Segundo Confino (1972), o grupo que é considerado a primeira geração da intelligentsia russa é herdeiro direto desse contexto de entrada de novas ideias ocidentais misturada com o aumento da censura. Os homens que compunham esse grupo (já adultos nos anos 1830 e 1840) tinham ideias heterogêneas - de hegelianismo de direita a socialismo -, mas compartilhavam alguns pontos em comum: crença na liberdade de expressão, na liberdade do homem (eram, portanto, contra a servidão dos camponeses, também chamados de mujiques), na ciência, na educação e na inserção da Rússia no contexto intelectual da Europa. Além disso, 
opunham-se aos eslavófilos, que propunham uma volta às tradições originais russas - tidas pela intelligentsia como obscurantistas. Pertence a essa geração não apenas o próprio Turgueniev, mas também os "pais" presentes no romance Pais e Filhos, em especial os irmãos Nicolau e Páviel.

A segunda geração dessa intelligentsia, chamada de "geração dos filhos", é a dos homens dos anos 1860. Tem como fenômeno central o niilismo e é marcada pela radicalização do pensamento e pela adesão de membros das camadas mais comuns (como camponeses, artesãos e comerciantes). Segundo Confino,

The central tenets of the nihilist outlook were a positivist, philosophical materialism, fading into scientism; a belief in the intrinsic value as well as in the progressive social function of the natural sciences; a somewhat rudimentary aesthetic realism" (CONFINO, 1972: 129-130) ${ }^{2}$.

É nessa geração, portanto que se encontram os “filhos" presentes no romance: os protagonistas Bazárov e Arcádio. Turgueniev escreveu esse romance por notar as diferenças que surgiam entre a sua geração e a próxima - esse conflito entre o velho e novo vai ser o tema central da obra.

Quando Arcádio volta para o lugar onde cresceu para visitar seu pai, Nicolau Pietróvitch, leva consigo seu amigo e mentor, Eugênio Bazárov. As oposições entre as gerações começam a ser estabelecidas já nas

2 Tradução livre: Os princípios centrais da perspectiva niilista eram um materialismo filosófico e positivista, misturando-se a um cientificismo; uma crença no valor intrínseco assim como na função social progressiva das ciências naturais; uma estética um tanto rudimentar de realismo. 
primeiras cenas, à medida em que Nicolau conversa com seus convidados e vai tomando conhecimento das ideias niilistas que eles seguem. Os jovens rejeitam toda a autoridade e o que consideram romântico, ou seja, que não pode ser determinado pela razão e pelos métodos das ciências sociais. Entende-se como uma "droga romântica", portanto, a apreciação da arte e da natureza. Esse é o principal ponto de atrito estabelecido com Nicolau, que tem uma apreciação extremamente grande da música, da poesia e da natureza - elementos que o tornam atrasado sob o ponto de vista dos jovens. Após entreouvir seu filho e Bazárov condenarem a leitura de seu livro de poemas, Nicolau desabafa para o irmão:

- Efetivamente - observou Nicolau Pietróvitch. - É egoísta. O que não compreendo é o seguinte: parece que faço tudo de acôrdo com a época: instalei os mujiques, organizei uma fazenda, e, por isso, em tôda a província sou chamado de vermelho. Leio, estudo e quero estar ao alcance das exigências modernas. E êles afirmam que sou um homem acabado. Começo a acreditar que realmente o sou (TURGUENIEV, 1971: 59).

Conforme demonstra Gary R. Jahn (1977), enquanto a reação de Nicolau a essas mudanças é passiva - no sentido de buscar uma conciliação e a aprovação do filho para não perder a conexão com ele -, Páviel responde agressivamente às ideias manifestadas por Bazárov, questionando-o constantemente sobre suas convicções. Após Bazárov manifestar seu desgosto pela aristocracia, Páviel imediatamente o confronta: 
Ouso dizer ainda que sou conhecido como homem liberal e progressista. Por isso mesmo respeito os verdadeiros aristocratas. [...] lembre-se, meu caro senhor, [...] dos aristocratas ingleses. Êles não desistem do mínimo dos seus direitos e respeitam os alheios. Exigem que se cumpram tôdas as obrigações para com êles e por isso mesmo cumprem suas obrigações. A aristocracia libertou a Inglaterra e defende a sua liberdade (TURGUENIEV, 1971: 61).

Bazárov rapidamente questiona qual a utilidade que Páviel representava para a sociedade russa enquanto vivia sua vida reclusa no campo. De acordo com Confino (1972), essa crítica ao caráter ocioso da geração de 1840 é colocada como um dos principais ataques encabeçados pelos niilistas da nova geração. Segundo Berlin (1988), é possível perceber influências de Bakunin na negação veemente de Bazárov às estruturas abstratas e à aristocracia, pois, ao negar toda a autoridade, admite que as instituições atrasadas devem ser destruídas independentemente dos danos momentâneos que isso trouxer para a sociedade. Bazárov expressa uma crítica ainda maior sobre a utilidade dos intelectuais, que discutem teoricamente temas abstratos como arte, parlamentarismo e justiça enquanto:

[...] o problema é o pão de cada dia, quando uma superstição brutal nos sufoca, quando tôdas as nossas sociedades comerciais ou industriais por ações rebentam, porque faltam homens honestos, quando a própria liberdade, que tanto preocupa o govêrno, dificilmente nos será proveitosa, porque o nosso mujique é capaz de roubar a si mesmo, só para se embriagar na taverna (TURGUENIEV, 1971: 66). 
Cadernos de Clio, Curitiba, v. 9, nº. 1, 2018

Essa crítica vocalizada por Bazárov parece ser compartilhada pelo autor do livro, pois Ivan Turgueniev foi uma pessoa que estava a par dos diversos pensamentos que permeavam a Rússia em seu contexto hegelianismo, materialismo, socialismo, positivismo, populismo, coletivismo. Entretanto, segundo Isaiah Berlin:

[...] tudo isso parecia-lhe mera abstração, sucedâneo da realidade, em que muitos acreditavam e poucos tentavam viver. Tratava-se de doutrinas a que a vida, com sua superfície irregular e os formatos desordenados do verdadeiro caráter e atividades humanos, certamente resistiria e esfacelaria com elas, caso algum dia se fizesse um sério esforço para transpô-las à prática (BERLIN, 1988: 269).

Essa observação de Turgueniev sobre os intelectuais do período está claramente presente em sua obra na figura de Eugênio Bazárov. Niilista, positivista e materialista, a personagem nega qualquer manifestação que não seja objetiva e empiricamente comprovada, demonstrando também um desprezo pelo que considera "ideais românticos" de honra e superioridade manifestados na geração anterior. Mesmo assim, Bazárov se apaixona por Ana Odintsova, mulher da alta-sociedade, quando visita sua residência. Bazárov entra em crise não apenas por ter traído seus próprios ideais, mas também por ter seu amor negado. Esse acontecimento marca a decadência da personagem na narrativa, que vai se tornando cada vez mais infeliz e, no final, se permite morrer ao não lidar com um ferimento obtido na realização de uma autópsia. A impossibilidade de viver uma ideologia abstrata também é marcada na personagem de Arcádio, 
discípulo de Bazárov, que nega seu mestre e suas ideias para viver casado com Cátia, caçula de Madame Odintsova, e cuidando dos afazeres do campo. A segunda visita que os protagonistas realizam, portanto, é um ponto chave no romance por marcar a expressão máxima da impossibilidade desses personagens viverem seus ideais à risca.

Outro ponto importante no qual o realismo cético de Turgueniev se manifesta é na sua postura frente às idealizações dos camponeses promovidas por adeptos do populismo como Alexandre Herzen. Apesar de ser extremamente contra a servidão, Turgueniev acreditava que o camponês russo "é o pior de todos os conservadores e pouco se importa com ideias liberais" (BERLIN, 1988: 270). Esse pensamento também é fortemente observável em Pais e Filhos: apesar da abolição da servidão ser considerada uma medida de senso comum, realizada pelos pais de ambos os protagonistas, Nicolau Pietróvitch passa o romance inteiro sofrendo com a comuna camponesa - reclamando da preguiça e deslealdade dos mujiques. A figura de Bazárov também é importante nesse aspecto, pois se dá muito bem com os mujiques, apesar de se dirigir a eles apenas em tom sarcástico e presunçoso. Bazárov despreza os camponeses por eles serem ignorantes e supersticiosos, mas se gaba por possuir esse conhecimento prático sobre eles - que sugere se dar por sua origem mais humilde, que surtiria nos mujiques uma simpatia e identificação. Turgueniev, entretanto, após escrever uma das últimas conversas que Bazárov tem com um camponês, revela: 
Bazárov, tão inteligente, observador e conhecedor dos mujiques (como teve ocasião de afirmar nas discussões com Páviel Pietróvitch), êsse mesmo Bazárov nem suspeitava que aos olhos dos mujiques êle não passava de uma espécie de palhaço... (TURGUENIEV, 1971: 222).

A religião só é tratada na obra como uma dimensão atrasada da sociedade mais humilde da Rússia. Devido a isso, ela é representada nos mujiques e nos pais de Bazárov, que são de origem menos abastada. A terceira visita realizada por Arcádio e Bazárov é justamente à residência dos pais do último, Vassíli Ivánovitch e Arina Vassílievna. A religiosidade é a característica dominante da mãe do personagem, que acredita em todas as sortes de misticismo. Assim caracterizada, Arina é apresentada por Turgueniev como

uma legítima representante da antiga burguesia russa. Devia ter nascido há duzentos anos, no período moscovita. Muito religiosa e sensível, acreditava em tôda espécie de superstições, encantamentos, cartomancia e sonhos (TURGUENIEV, 1971: 146).

O pai de Bazárov, da mesma maneira que Nicolau, tenta se aproximar do filho ao estudar e praticar as novas ciências e tem vergonha de admitir que é tão religioso quanto sua esposa. Essa imagem é desconstruída e dá lugar ao total sentimentalismo após a morte de Bazárov, quando o epílogo da obra sugere que nenhum deles conseguiu superar racionalmente a perda do filho e passaram o resto de suas vidas lamentando ao lado do túmulo. 
Cadernos de Clio, Curitiba, v. 9, nº. 1, 2018

A visão negativa e decadente do passado russo apresentada em Arina Vassílievna também é presente na figura de Princesa $K$, tia de Ana Odintsova. Essa personagem é apresentada como uma senhora mal-humorada que espera ser tratada com respeito devido ao seu nascimento, mas na verdade é terminantemente ignorada por todos ao seu redor. Sua presença é narrada como desagradável, e só é convidada para morar com madame Odintsova após seu marido morrer, para manter o status da residência e garantir a boa educação de Cátia, a irmã caçula.

\section{Conclusões}

No século XIX, diversas maneiras de se ver o mundo e interpretar a história se relacionavam. O regime moderno de historicidade, as filosofias da história estabeleciam um futuro para o qual as sociedades caminhavam numa linha progressiva. Esse futuro idealizado seria a realização última da história, sendo o tempo presente apenas um estágio em direção a esse fim (HARTOG, 2017). É nesse contexto também que a História passa a se oficializar como disciplina científica, buscando estabelecer métodos objetivos tais quais os das ciências naturais para se legitimar como tal. Evidentemente, a visão positiva do avanço da civilização não era unânime, havendo diversas vozes mais céticas que permeavam a discussão (ROSSI, 2000). O romantismo tem papel muito importante nesse contexto por trazer um maior foco às particularidades do povo que eram perdidas nas grandes generalizações das filosofias da história. Segundo François Hartog: 
Se, com o século XIX, a História bem se tornou para todos uma evidência, os historiadores e os escritores não se apropriam dela da mesma maneira. Nesse jogo por e contra o regime moderno de historicidade, os primeiros estão mais do lado do "por" (com o tempo como progresso), ao menos na primeira metade do século, enquanto os segundos, que não são necessariamente contra, mostram-se mais requisitados pelo descontínuo, mais atentos ao anacronismo e às temporalidades desarmônicas, mais sensíveis aos reflexos do simultâneo e do não-simultâneo e aos dramas dos quais ele é o prenúncio (HARTOG, 2017: 141).

Os romances em si - não apenas os românticos -, portanto, são fundamentais para se compreender a realidade mais próxima da população no século XIX, aspecto que não era muito abordado pela historiografia. $\mathrm{O}$ realismo de Turgueniev, presente em todas as suas obras, é muito eficiente em mostrar a heterogeneidade que se apresentava no cotidiano do século XIX. Ao comunicar as controvérsias entre intelectuais da geração de 40 e da geração de 60, o romance Pais e Filhos rendeu-lhe hostilidades tanto de segmentos da esquerda quanto da direita. A personagem Bazárov foi uma figura de recepção extremamente polêmica por parte de todos os intelectuais russos do período. De acordo com Berlin (1988), alguns segmentos da esquerda o consideraram uma representação horrenda do racionalismo ao negar a arte, outros reconheciam nele o fervor de seguir sua ideologia; por parte da direita, alguns acreditavam que Bazárov permitia que os novos niilistas se legitimassem e o odiavam por isso, enquanto outros o apreciaram como uma representação fiel dos aspectos negativos da juventude. 
Uma questão que atesta em favor do comprometimento que Turgueniev tinha com o Realismo e que possibilitou as respostas múltiplas à sua obra se dá na conclusão do livro. Apesar de, desde o começo, estabelecerem-se grandes oposições entre pais e filhos - culminando até mesmo num duelo físico entre Bazárov e Páviel -, é possível perceber ao final que há mais continuidades e relações do que diferenças. A obra não apresenta heróis nem vilões e muitos personagens centrais terminam com visões diferentes das que apresentavam no início. Páviel Pietróvitch, que desde o começo é apresentado como a oposição mais ferrenha aos ideais de Bazárov, passa a concordar com algumas de suas visões após seu duelo:

- Começo a pensar que Bazárov tinha razão, quando me acusava de aristocratismo. Não, meu caro, não nos convém mais exibir-nos e pensarmos na alta sociedade. Somos homens antigos e pacíficos. Já é tempo de abandonarmos tôdas as vaidades. Resta-nos, como diz, cumprir nosso dever. E veja: podemos ainda receber a felicidade em troca de tudo isso (TURGUENIEV, 1971: 197).

Arcádio, como já anteriormente citado, nega o niilismo e seu antigo mestre para se casar com Cátia, e termina morando junto com seu pai e o auxiliando nas tarefas da fazenda - recuperando o laço estreito entre os dois que havia sido enfraquecido pelos conflitos desenvolvidos ao longo do romance. Bazárov, além de ter se apaixonado, morre questionando se foi realmente útil à sociedade: em seus delírios de morte, pergunta-se "sou necessário à Rússia? Não, provavelmente não o sou. E quem é necessário? O sapateiro, o alfaiate, o açougueiro... que vende carne... o açougueiro" 
(TURGUENIEV, 1971: 235). Acredita no progresso que a ciência, industrialização e modernização podem trazer, mas percebe que esses elementos não chegam à maioria camponesa russa.

Considerando o que foi apresentado, é possível concluir que a análise do romance, juntamente com o estudo de seu autor e contexto histórico, é uma ferramenta muito rica para estudar a modernidade. Enquanto a historiografia se desenvolvia em meio a contradições internas e externas para se afirmar como ciência, focando principalmente no Estado e suas grandes figuras, os romances fornecem uma visão das "fissuras do regime moderno" (HARTOG, 2017: 176) e permitem compreender melhor a diversidade de ideias e situações que circulavam no período.

\section{Referências Bibliográficas}

BERLIN, Isaiah. "Pais e Filhos - Turgueniev e a crítica situação liberal". In: Pensadores Russos. São Paulo: Companhia das Letras, 1988, pp. 262-298.

CONFINO, Michael. On Intellectuais and Intellectual Traditions in Eighteenth- and Nineteenth-Century Russia. Daedalus, Cambrigde: MIT Press, Vol. 101, No. 2, 1972, pp. 117-149.

HARTOG, François. Crer em história. Belo Horizonte: Autêntica, 2017.

JAHN, Gary R. Character and Theme in "Fathers and Sons". College Literature, Baltimore: Johns Hopkins University Press, Vol. 4, No. 1, 1977, pp. 80-91.

ROSSI, Paolo. Naufrágios sem espectador. A ideia de progresso. São Paulo: Unesp, 2000. 
Cadernos de Clio, Curitiba, v. 9, nº 1, 2018

TURGUENIEV, Ivan. Pais e Filhos. Coleção "Os Imortais da Literatura Universal”, fascículo 14. São Paulo: Abril, 1971.

Recebido em: 17/08/2019

Aceito em: 19/05/2020 